NASA Technical Memorandum 100973

\title{
Small-Droplet Spray Measurements With a Scattered-Light Scanner
}

\author{
(NASA-TH-100973) SMALI-DROPLET SPEAY \\ MEASUREMENTS NITH A SCATTEBED-LIGHT SCANNER \\ (NASA) $16 \mathrm{p}$ \\ CSCí $14 \mathrm{~B}$
}

N88 -26645

Unclas

$63 / 35 \quad 0154967$

Robert D. Ingebo and Donald R. Buchele

Lewis Research Center

Cleveland, Ohio

Prepared for the

Second Symposium on Liquid Particle Size Measurement Techniques

sponsored by the American Society for Testing and Materials

Atlanta, Georgia, November 9-11, 1988 


\section{SMALL-DROPLET SPRAY MEASUREMENTS WITH A SCATTERED-LIGHT SCANNER}

Robert D. Ingebo and Donald R. Buchele

National: Aeronautics and Space. Administration

Lewis Research Center

Cleveland, Ohio 44135 U.S.A.

\section{ABSTRACT}

Interacting two-phase flow through pneumatic two-fluid nozzles was investigated to determine the effect of nitrogen gas mass-velocity on the Sauter mean diameter of water sprays produced by the "breakup of small diameter liquid-jets in high velöity gas streams: Tests were conducted primarily in the aerodynamic-stripping regime of liquid-jet atomization. It was found that the loss of droplets due to vaporization and dispersion had a marked effect on drop size measurements. A scattered-light scanner; developed at NASA Lewis Research Center was used to measure Sauter mean diameters, $D_{32}$, as small as $5 \mu \mathrm{m}$, which were correlated with nitrogen gas mass-velocity to give the following expression:

$$
D_{32}^{-1}=11.7\left(\rho_{n} v_{n}\right)^{1.33}
$$

where $D_{32}$ and $\rho_{n} V_{n}$ are given in centimeters and $\mathrm{g} / \mathrm{cm}^{2}-\mathrm{sec}$, respectively. The exponent 1:33 is the same as that predicted by atomization theory for liquid-jet breakup in high velocity gas streams.

\section{NOMENCLATURE}

Ao. atomizer orifice area, $\mathrm{cm}^{2}$

b drop size parameter in Nukiyama-Tanasawa expression, cm

c drop size parameter in Rosin-Rammler expression, cm

$D_{j} \quad$ diameter of $i$ th $d r o p, c m$

Dv.5 volume median drop diameter for entire spray, cm

$D_{V .5}^{l}$ volume median drop diameter for line-of-sight measurements; cm 
Dv.75 drop diameter such that 75 percent of the total liquid volume is in drops of smaller diameter

$\mathrm{D}_{31} \quad$ volume-1 inear mean drop diameter, $\left[\sum_{i} \mathrm{D}_{i}^{3} / \sum_{i} \mathrm{D}_{i}\right]^{0.5} \mathrm{~cm}$

$\mathrm{D}_{32}$ Sauter mean drop diameter, $\sum_{i} D_{i}^{3} / \sum_{i} D_{i}^{2}, \mathrm{~cm}$

$N_{n}$ exponent for Nukiyama-Tanasawa drop size distribution expression

$\mathrm{N}_{\mathrm{r}}$ exponent for Rosin-Rammler drop size distribution expression

$n$. number of droplets

V...fluid velocity, $\mathrm{cm} / \mathrm{sec}$

$v$ volume fraction of droplets with diameters less than or equal to $x$

W. Weight flow of fluid, g/sec

$x$. droplet diameter in drop size distribution expressions, $\mathrm{cm}$

$\bar{x} \quad \therefore \quad$ axial downstream spray sampling distance,. $\mathrm{cm}$.

$\rho \quad$ : : dẹnsity of fluid, $\mathrm{g} / \mathrm{cm}^{3}$

Subscripts

$n \quad n i t r o g e n$ gas

water

\section{INTRODUCTION}

In the application of atomization techniques to the study of icing clouds and fuel sprays, there is considerable demand for spray nozzles capable of producing small-droplet sprays with Sauter mean diameter, $\mathrm{D}_{32}$, of $10 \mu \mathrm{m}$ or less. Along with small droplet sprays, drop sizing instruments are needed that are capable of accurately measuring drop sizes in high number-density clouds of small droplets. In the present investigation, pneumatic two-fluid atomizers were used at high fluid pressures to produce sprays with values of $D_{32}$ considerably smaller than $10 \mu \mathrm{m}$, as measured with a scattered-light scanner developed at NASA Lewis. 
In the spray study discussed in Ref. 1 , it was found that the effect of droplet vaporization on spray measurements could be minimized by taking samples close to the atomizer, i.e., $2.2 \mathrm{~cm}$ downstream of the atomizer orifice. This technique gave the best agreement between theoretical and experimental effects of nitrogen gas flowrate on Sauter mean, $D_{32}$, volume median, $D_{v} .5$, and volumelinear mean, $D_{31}$, diameters. Therefore, in the present study, the Sauter mean diameter was measured in most cases at a sampling distance of $2.2 \mathrm{~cm}$ downstream of the nozzle orifice with the scattered-light scanning instrument.

Also, in the spray study of Ref. I it was found that the reciprocal of the Sauter mean drop diameter, $D_{32}$, could be correlated with nitrogen gas weight flowrate, $w_{n}$, raised to the 1.33 power, which agrees well with atomization theory: for liquid-jet breakup in high velocity gas streams. As a continuation of that study, the present investigation was initiated to extend experimental conditions to include a variation in nozzle orifice diameter.: By using four differently sized atomizers, it was possible to investigate the effects of nitrogen gas mass-velocity, $\rho_{n} V_{n}$, on the Sauter mean dropsize of the spray. Values of $\rho_{n} V_{n}$ were calculated from nitrogen gas flowrate per unit area, $W_{n} / A_{0}$, and values of $A_{0}$ were varied from 0.0804 to $0.246 \mathrm{~cm}^{2}$ using four different nozzle orifices.

\section{APPARATUS AND PROCEDURE}

The pneumatic two-fluid nozzle was mounted in the test section as shown in Fig. I which also shows the optical path of the scattered-light scanner. A detailed diagram of the atomizer is shown in Fig. 2 .

The Scattered-Light Scanner

The optical system of the scattered-light scanner shown in Fig. I consists of a laser beam expander with a spatial filter, rotating scanning slit, and a detector. The instrument measures scattered light as a function of scattering 
angle by repeatedly sweeping a variable-length sit in the focal plane of the collecting lens. The data obtained is scattered-light energy as a function of the scattering angle relative to the laser beam axis. This method of particle size measurement is similar to that given in Ref. 2 .

It has been shown in Ref. 3 that measurements of four points on the plot of scattered-light energy normalized to the maximum energy and plotted against scattering angle can be used to determine the Sauter mean diameter, the volume median diameter, the volume linear diameter, and the 75-percent volume diameter. The dispersion of the size distribution may also be determined using the four points, for each of the four characteristic diameters as shown: in Fig. 3. It should be noted that in Ref. 3 it is shown that this method of determining the four characteristic drop diameters and dispersion of drop sizes can be used independent of the particle size distribution function. For a typical measurement, the scan is repeated 60 times per second to average out any temporal variations in the energy curve.

Spray pattern effects were minimized by measuring characteristic drop diameters while the entire spray was being sampled. Reproducibility using this technique has been shown to be within \pm 5 percent. Calibration was accomplished with five sets of monosized polystyrene spheres having diameters of $8,12,25$, 50, and $100 \mu \mathrm{m}$. Since the sprays were sampled very close to the atomizer orifice, they contained a relatively high number-density of very small drops. As a result, the light-scattering measurements required correction for multiple scattering as described in Refs. 3 and 4 for the case of high number-density sprays. Drop size measurements were also corrected to include Mie scattering theory when very small droplet diameters; i.e., <10 $\mu \mathrm{m}$, were measured.

In the present study, the scattered-light scanner sampled the entire spray with a $4.4-$ by $1.9-\mathrm{cm}$ rectangular laser beam. Later in this study, the long 
dimension of the laser beam was reduced from 4.4 to $0.64 \mathrm{~cm}$ in ordèr to have a small beam for traversing the spray at various radial positions and thereby increase the spatial resolution and make line-of-sight measurements.

In applying various characteristic drop sizes to spray studies, the Sauter mean diameter, $D_{32}$, is generally preferred for use in the study of fuel-spray combustion. The volume median diameter, $D_{V .5}$, is generally preferred in characterizing small-droplet icing-clouds to determine their effect on aircraft performance under icing conditions. The characteristic diameter, $D_{V} .75$, which is defined as the drop size at which 75 percent of the total liquid volume of the spray is in drops of larger diameter and 25 percent is in drops of smaller diameter, is very useful as a measure of the relative importance of the large drops. Especially when it is used in the ratio $D_{V} .75 / D_{V} .5$, which is very useful in indicating the transition of drop size data from a single mode to a bimodal distribution of spray particle sizes. The volume-linear mean diameter, $D_{31}$, has been used to some extent in the study of vaporizing sprays as an indicator of the relative droplet surface-area.

\section{Experimental Procedure}

To study liquid jet breakup, a pneumatic two-fluid atomizer was used to produce clouds of small droplets. A diagram of the atomizer is shown in Fig. 2. It was mounted at the center line of a 24-cm-diameter duct and operated over a pressure range of 0.2 to $1.0 \mathrm{MPa}$ for both water and nitrogen gas. The entire spray was sampled at distances of $2.2,4.4$, and $6.7 \mathrm{~cm}$ downstream of the atomizer orifice with the 4.4- by 1.9-cm rectangular laser beam. Water at a temperature of $293 \mathrm{~K}$, measured with an I.C. thermocouple, was axially injected from the atomizer into the airstream by gradually opening a control valve until the desired flow rate was obtained as indicated by a turbine flowmeter. Nitrogen gas was then turned on to atomize the water jet 
and nitrogen weight flowrate-was measured: with a $0.51-\mathrm{cm}-\mathrm{di}$ ameter sharp edge orifice. When air, nitrogen, and water flowrates were set, volume median and other characteristic drop diameters and exponents for drop size distribution expressions were determined using the scattered-light scanner.

\section{EXPERIMENTAL RESULTS}

The effect of axial sampling distance on characteristic diameters was investigated and the effect of gas mass-velocity on $D_{32}$ was determined. Finally, line-of-sight profiles of the characteristic drop size, $D_{V} .5$, were obtained. for four similar atomizers and characteristic exponents for RosinRammler and Nukiyama-Tanasawa drop size distribution expressions were also determined.

Effect of Axial Sampling Distance on Characteristic Drop Size

As shown in Fig. 4, the entire spray was sampled at axial distances of $\bar{x}=2.2,4.4$, and $6.7 \mathrm{~cm}$, where $\bar{x}$ is the distance from atomizer orifice to the center line of the laser beam as measured along the spray center line. The water flowrate was held constant within \pm 5 percent at $3.15 \mathrm{~g} / \mathrm{sec}$ and characteristic drop diameters, $D_{v .5}$ and $D_{32}$, were measured and plotted against nitrogen gas flowrate, $W_{n}$, as shown in Figs. $5(a)$ and (b). All of the atomizers were used for this series of tests, and the data plotted in Fig. 5(a) show that:

$$
D_{v .5}^{-1} \sim W_{n}^{n}
$$

In Table I, from Ref. 1, values of the exponent $n$ are given for sampling distances of $\bar{x}=2.2,4.4$, and $6.7 \mathrm{~cm}$, respectively. Figure $5(\mathrm{~b})$ gives similar results for the Sauter mean diameter, $D_{32}$.

The expressions, $D_{v .5} \sim w_{n}^{1.33}$ as obtained at $x=2.2 \mathrm{~cm}$, agrees with 
that given by atomization theory for liquid jet breakup in the accelerationwave regime (Ref. 5). This agreement of experimental data with theory was attributed to the fact that measurements obtained at $x=2.2 \mathrm{~cm}$ are less affected by vaporization and dispersion of the very small droplets as compared with measurements made farther downstream from the atomizer orifice. Values of the exponent, $n$, obtained in other experimental studies (Refs. 5 to 10) are also shown in Table II for comparison with atomization theory. Measurement techniques and instrumentation have not yet been sufficiently developed or standardized to such an extent that good agreement might be expected among different investigators.

- Effect of Gas Mass-Velocity on Sauter Mean Diameter

As shown in Fig. 4, the entire spray was sampled at an axial distance of $\bar{x}=2.2 \mathrm{~cm}$ downstream of the atomizer orifice. Values of the Sauter mean diameter, $D_{32}$, for the four different atomizers are plotted against nitrogen gas flowrate per unit orifice area as shown in Fig. 6, which gives the following relationships: $D_{32}^{-1}=11.7\left(W_{n} / A_{0}\right)^{1.33}$ or in terms of gas massvelocity, $D_{32}^{-1}=11.7\left(p_{v} v_{n}\right)^{1.33}$.

The exponent 1.33 agrees very well with atomization theory for liquidjet breakup in high velocity gas streams. This agreement is attributed to the fact that measurements obtained at $\bar{x}=2.2 \mathrm{~cm}$ are less affected by vaporization and dispersion of small drops than measurements made farther downstream of the atomizer orifice.

$$
\text { Radial Profiles of Characteristic Drop Diameter, D'v.5 }
$$

The beam height of the scattered-light scanner was reduced from 4.4 to $0.64 \mathrm{~cm}$ and 1 ine-of-sight measurements of the characteristic drop diameter were made through the spray at several distances from the spray centerline. 
Measurements were obtained for the four atomizers at constant water and nitrogen gas flowrates and an axial downstream sampling distance of $\bar{x}=4.4 \mathrm{~cm}$. Values of $D_{v .5}^{\prime}$ are plotted against horizontal location as shown in Fig. 7 .

Peak values of $D_{v .5}^{\prime}$ at the liquid jet center line were reduced nearly 50 percent, from approximately 60 to $30 \mu \mathrm{m}$, when the nitrogen gas flowrate was increased from 1.59 to $2.59 \mathrm{~g} / \mathrm{sec}$. A similar reduction in $D_{v .5}^{\prime}$ occurred near the outer edges of the sprays. The asymmetry of the spray profiles was attributed to the effect of gravity on the drops and also to slight misalignments of the center tubes of the various atomizers. Values of $D_{v .5}^{\prime}$ show relatively good uniformity of drop size for the four atomizers. Differences in values of $D_{v .5}^{\prime}$. for the four atomizers were on the order of 10 to 20 percent.

Characteristic Exponents for Drop-Size Distribution Expressions

The scattered-light scanner gave data for the exponent $\mathrm{N}_{r}$, which appears in the Rosin-Rammler expression as follows (Ref. 11):

$$
\frac{d v}{d x}=\frac{N_{r} x^{N_{r}-1}}{c^{N_{r}}} e^{-(x / c)^{N_{r}}}
$$

Data were also obtained for the exponent $N_{n}$, which appears in the NukiyamaTanasawa expression as follows (Ref. 11):

$$
\frac{d v}{d x}=\frac{b^{6 / N_{n}}}{\Gamma\left(\frac{6}{N_{n}}\right)} x^{5} e^{-b x^{N_{n}}}
$$

From a plot of the data obtained with the four atomizers, as shown in Fig. 8, the following relation was determined:

$$
N_{r}=2.8 N_{n}^{0.45}
$$


which is the same as that derived in Ref. 1. Thus it was. found that although the downstream distance, $\bar{x}$, was varied from 2.2 to $6.7 \mathrm{~cm}$, the relation between the exponents was not appreciably affected by vaporization and dispersion of the small droplets.

\section{CONCLUDING REMARKS}

Spray measurements obtained with the scattered-light scanner gave good agreement with liquid-jet atomization theory. This good result was attributed to the rapid atomization of small liquid-jets and short breakup distances that may be obtained with a two-fluid atomizer. The good result may also be attributed to the fact that the sprays were sampled very close to the nozzle orifice, i.e., $2.2 \mathrm{~cm}$ downstream of the orifice, and thereby minimizing the loss of small droplets due to vaporization and dispersion affects.

\section{REFERENCES}

1. Ingebo, R.D., "Agreement Between Experimental and Theoretical Effects of Nitrogen Gas Flowrate on Liquid Jet Atomization, "AIAA Paper 87-2138, July 1987. (NASA TM-89821.)

2. Swithenbank, J., Beer, J.M., Taylor, D.S., Abbot, D., and McCreath, G.C., "A Laser Diagnostic Technique for the Measurement of Droplet and Particle Size Distribution," AIAA Paper 76-69, Jan. 1976.

3. Buchele, D.R., "Particle Sizing By Weighted Measurements of Scattered Light," NASA TM-100968.

4. Felton, P.G., Hamidi, A.A., and Aigal, A.K., 3rd International Conference on Liquid Atomisation and Spray Systems in ICLASS - 85, Vol. 2 , P. Eisenklam and A. Yule, Eds., Institute of Energy, London, 1985 , pp. IVA/4/1-IVA/4/11.

5. Adelberg, M., AIAA Journal, Vol. 6, No. 6, June 1968, pp. 1143-1147. 
6. Weiss, M.A., and Worsham, C.H., American Rocket Society Journal, Vol. 29, No. 4, Apr. 1959, pp. 252-259.

7. Wolfe, H.E:, and Andersen, W.H., in Proceedings of the 5th international Shock Tube Symposium, Z.I. Slawsky, J.F. Mouiton, Jr., and W.S. Filler, Eds., Naval Ordnance Lab., White Oak, MD, 1965, pp. 1145-1169. (Avail. NTIS, AD-638011.)

8. Kim, K.Y., and Marshall, W.R., Jr., AIChE Journal, Vol. 17, No. 3, May 1971 , pp. 575-584.

9. Nukiyama, S., and Tanasawa, Y., Transactions of the Society of Mechanical Engineers, Japan, Vol. 5, No. 18, Feb. 1939, pp. 63-75.

10. Lorenzetto, G.E., and Lefebvre, A.J., AIAA Journal, Vol. 15, No. 7, July 1977, pp. 1006-1010.

11. Mugele, R.A., and Evans, H.D., Industrial and Engineering Chemistry, Vol. 43, No. 6, June 1951, pp. 1317-1324.

TABLE I: - NITROGEN GAS FLOWRATE EXPONENT, $n$, AT SEVERAL SAMPLING LOCATIONS

\begin{tabular}{|c|c|}
\hline Sampling location, & $\begin{array}{c}\text { Exponent, } n \text {, for } n i \text { trogen } \\
\text { gas flowrate, } w_{n}\end{array}$ \\
\hline $\begin{array}{r}2.2 \\
4.4 \\
6.7 \\
\mathrm{a} 25.0\end{array}$ & $\begin{array}{l}1.33 \\
1.2 \\
1.0 \\
0.8\end{array}$ \\
\hline
\end{tabular}

aref. 1
TABLE II . - VELOCITY EXPONENT, N, FOR ACCELERATION WAVE BREAKUP OF LIQUID

$$
\text { [jets: } D_{\mathrm{m}}^{-1} \sim \mathrm{V}_{\mathrm{g}}^{\mathrm{n}} \text {.] }
$$

\begin{tabular}{|c|c|}
\hline Source & Exponent, $n$ \\
\hline $\begin{array}{l}\text { Theorya } \\
\text { Present study, } \bar{x}=2.2 \mathrm{~cm} \\
\text { Weiss and Worshamb } \\
\text { Wolfe and Andersen } \\
\text { Kim and Marshal }{ }^{\mathrm{e}} \\
\text { Nukiyama and Tanasawa, } \\
\bar{x}=5 \text { to } 25 \mathrm{~cm} \\
\text { Lorenzetto and Lefebureg }\end{array}$ & $\begin{array}{r}1.33 \\
1.33 \\
61.33 \\
1.33 \\
61.14 \\
1.0 \\
1.0\end{array}$ \\
\hline
\end{tabular}

aRef. 5 .

bRef. 6 .

CDrop size data for wax spheres.

dRef. 7 .

eRef. 8.

fRef. 9 .

gRef. 10. 


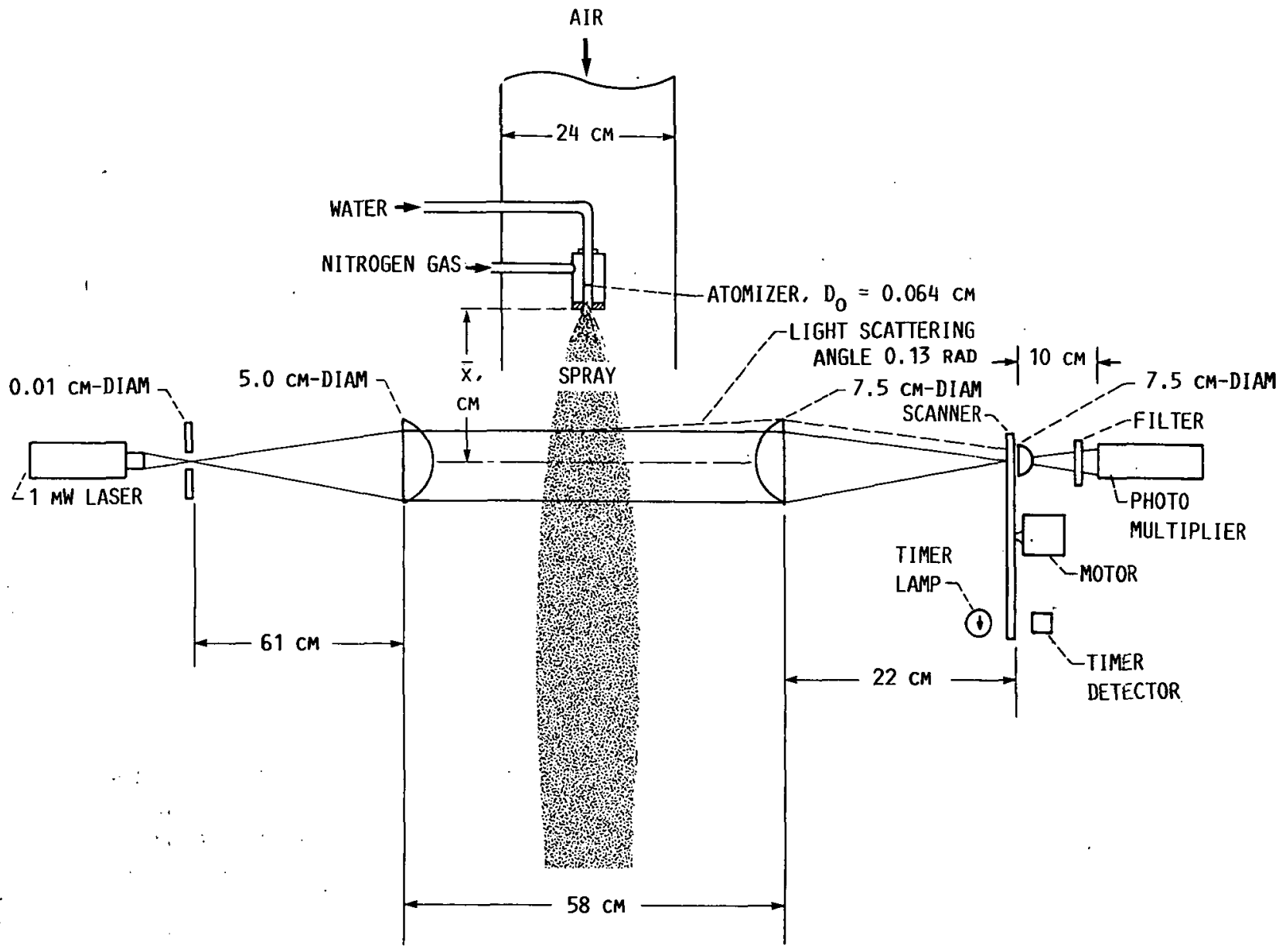

FIGURE 1. - ATMOSPHERIC PRESSURE TEST SECTION AND OPTICAL PATH OF SCATTERED-LIGHT SCANNER.

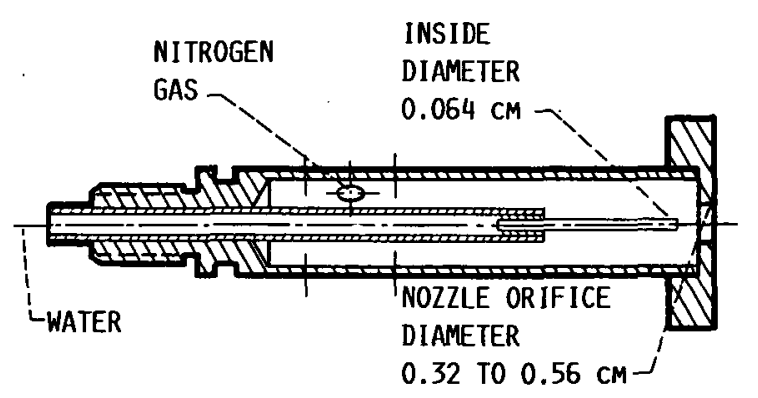

FIGURE 2. - DIAGRAM OF PNEUMATIC TWO-FLUID ATOMIZER. 


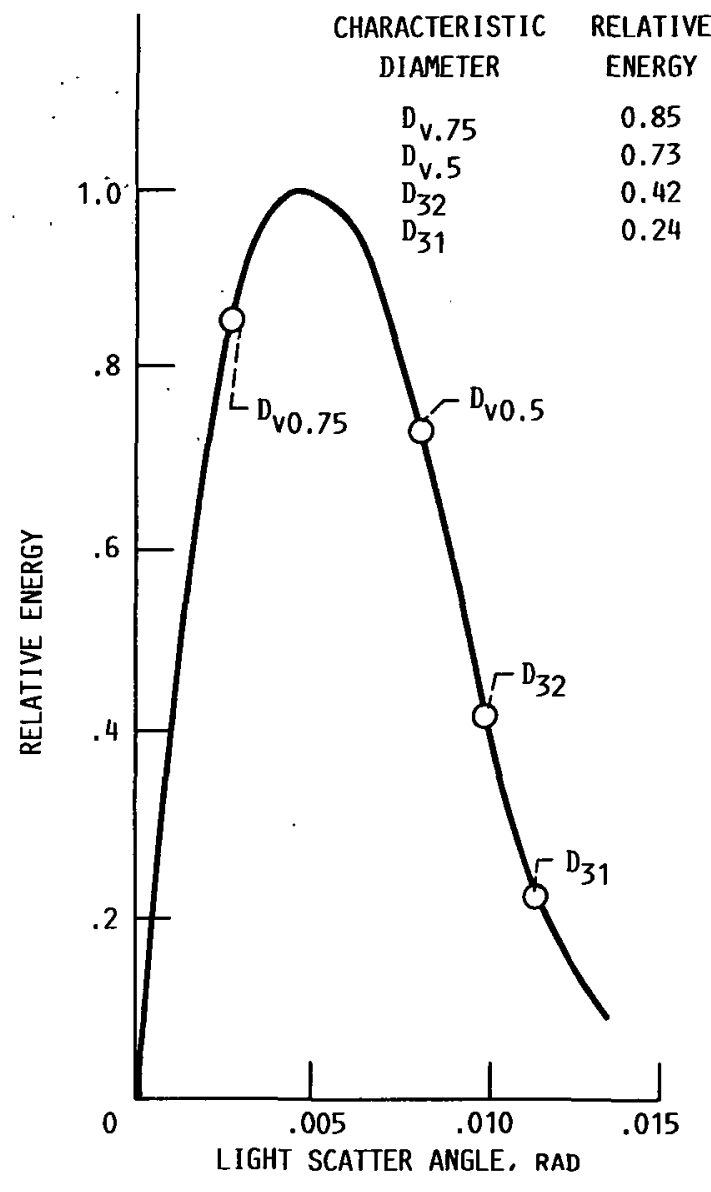

FIGURE 3. - TYPICAL SCATTERED-LIGHT ENERGY CURVE WITH FOUR CHARACTERISTIC DIAMETERS.

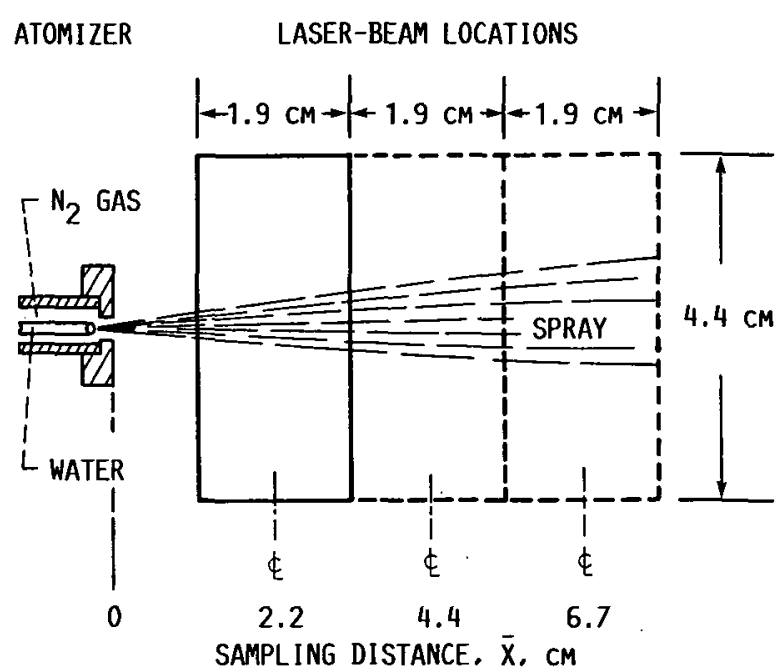

FIGURE 4. - DIAGRAM OF SAMPLING LOCATIONS OF $1.9 \mathrm{~cm}$ $\times 4.4 \mathrm{CM}$ LASER BEAM. 


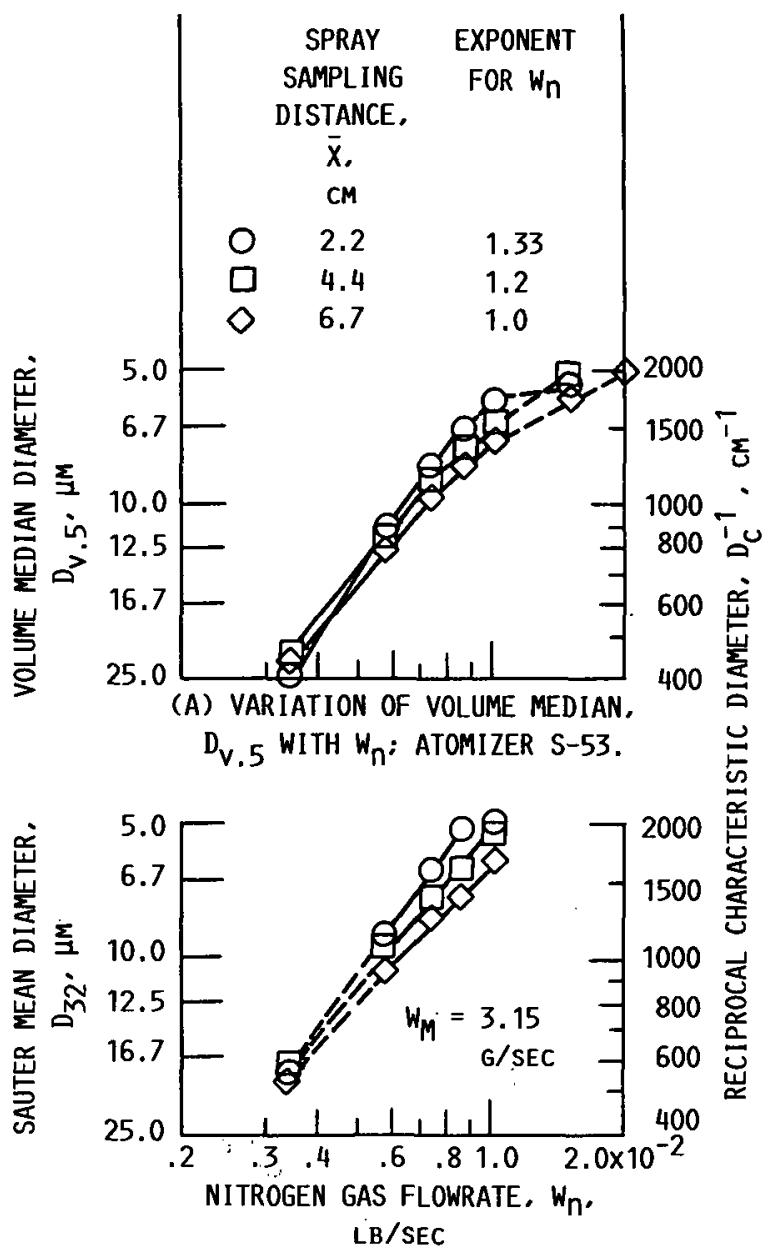

(B) VARIATION OF SAUTER MEAN DIAMETER, D 32 WITH $W_{n}$ : ATOMIZER S-94.

FIGURE 5. - EFFECT OF SPRAY

SAMPLING DISTANCE $X$. ON CHARACTERISTIC DROP DIAMETERS.

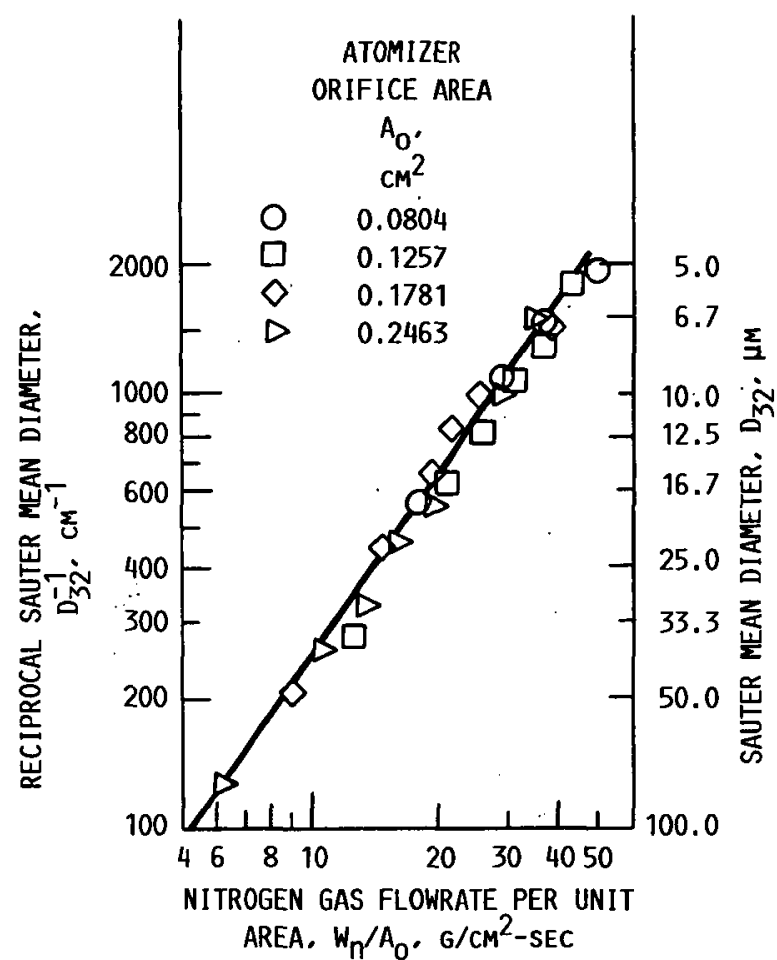

FIGURE 6. - CORRELATION OF $D_{32}$ WITH $W_{n} / A_{0}$. 

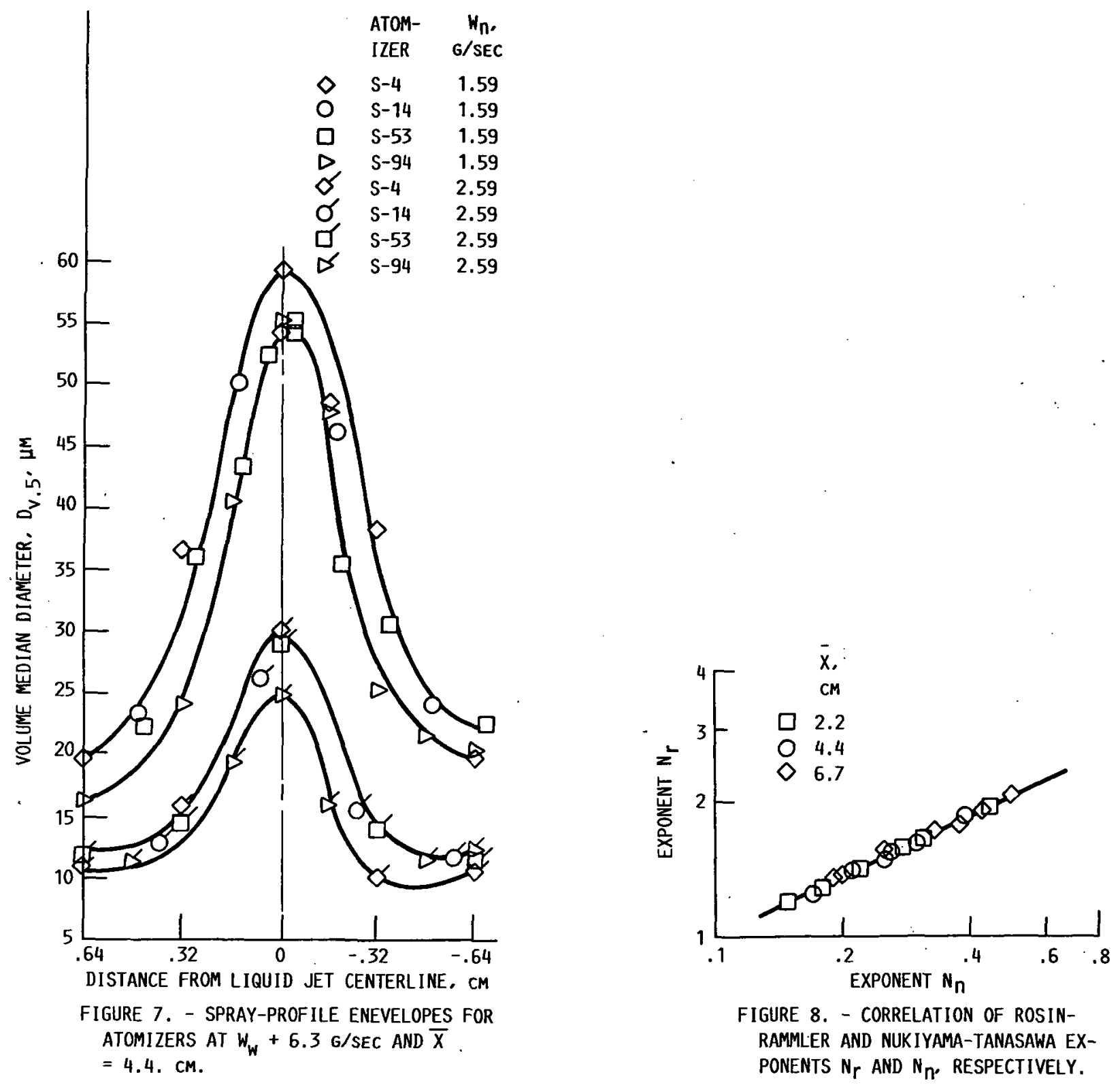

FIGURE 8. - CORRELATION OF ROSINRAMMLER AND NUKIYAMA-TANASAWA EXPONENTS $\mathrm{N}_{r}$ AND $N_{n}$, RESPECTIVELY. 


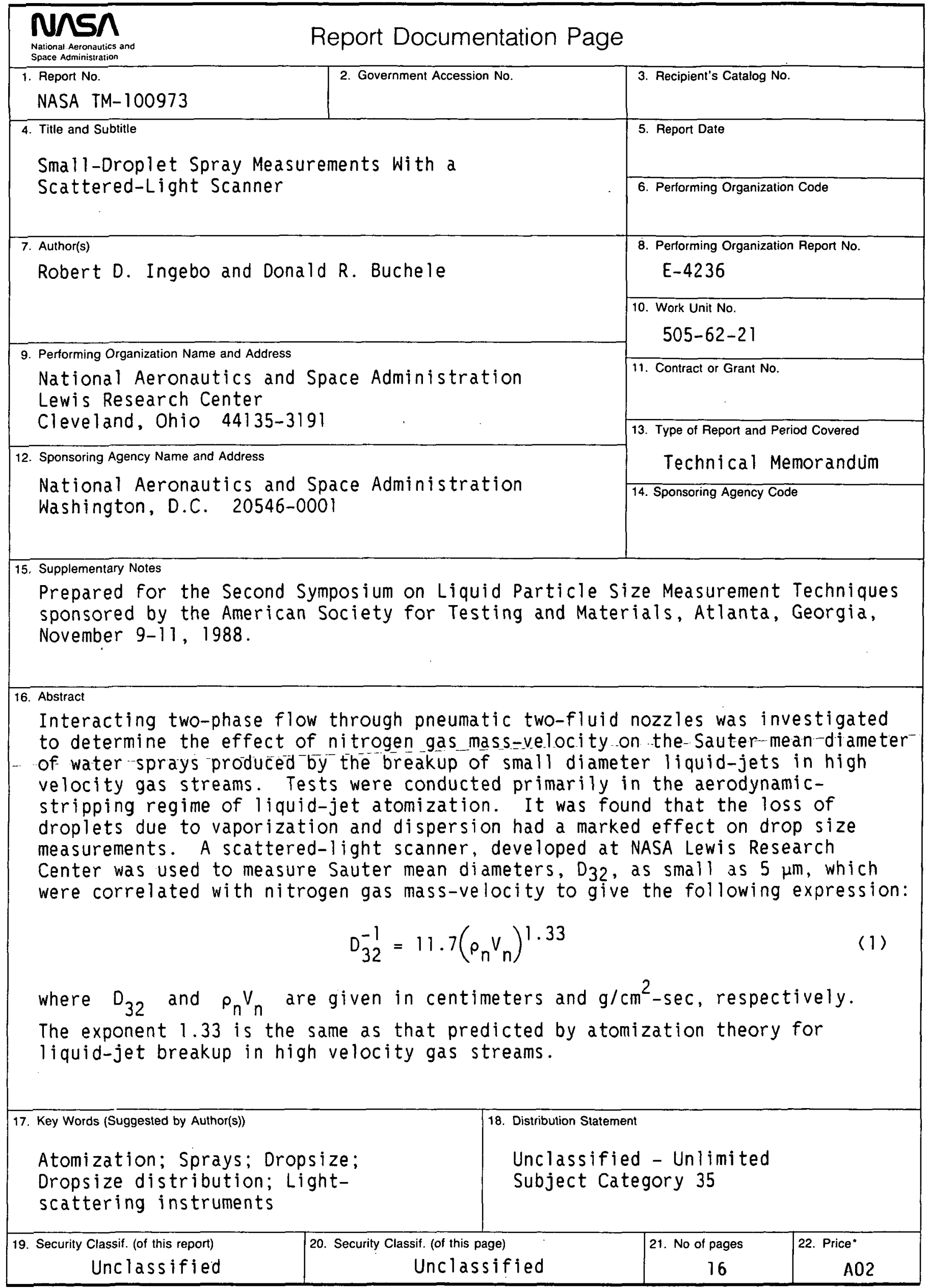


National Aeronautics and Space Administration

Lewis Research Center

Cleveland, Onio 44135

Otficial Business

Penalty for Private Use $\$ \mathbf{5 0 0}$
FOURTH CLASS MAIL

$|\||$

ADDRESS CORRECTION REQUESTED

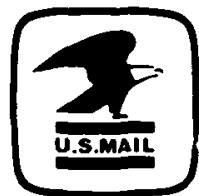

Poslage and Fees Paic

National Aeronautics a

Space Administration

NASA 451 